\title{
Nonalcoholic fatty liver disease and obesity ${ }^{1}$
}

\author{
Doença gordurosa não alcóolica do fígado e obesidade
}

\author{
Wilson Salgado Júnior², José Sebastião dos Santos ${ }^{3}$, Ajith Kumar Sankarankutty ${ }^{3}$, Orlando de Castro e Silva ${ }^{4}$ \\ 1. Work performed in the Gastroenterology Division, Bariatric Surgery Sector, Department of Surgery and Anatomy of the Faculty of \\ Medicine of Ribeirão Preto, University of São Paulo, Brazil (FMRP-USP) \\ 2. PhD, Assistant of Bariatric Surgery Sector of Division of Gastroenterology of the Department of Surgery and Anatomy,(FMRP-USP), Brazil. \\ 3. PhD, Professor of Division of Gastroenterology of the Department of Surgery and Anatomy, (FMRP-USP), Brazil. \\ 4. Full Professor, Head of Division of Gastroenterology of the Department of Surgery and Anatomy, (FMRP-USP), Brazil.
}

\begin{abstract}
Purpose: The aim of this review is to update concepts of the nonalcoholic fatty liver disease (NAFLD) and to establish a relationship between this condition and obesity. Methods: By means of a comprehensive literature review where special attention was devoted to articles published in the last 5 years, NAFLD is discussed in view of new concepts, diagnosis, staging, and treatment. Results: NAFLD is emerging as one of the main causes of chronic liver disease and it is believed to be the hepatic component of the metabolic syndrome, whose central features include obesity, hyperinsulinemia, peripheral insulin resistance, diabetes, dyslipidemia, and hypertension. The surgical treatment of morbid obesity is one of the options available for the treatment of NAFLD. Conclusion: Nonalcoholic fatty liver disease is strongly related with obesity.
\end{abstract}

Key words: Nonalcoholic Steatohepatitis. Hepatic Fibrosis. Morbid Obesity. Bariatric Surgery.

\section{RESUMO}

Objetivo: O objetivo deste artigo foi atualizar conceitos com relação à doença gordurosa não alcoólica do fígado (DGNAF) e a sua intrínseca relação com a obesidade. Métodos: Por meio de revisão bibliográfica, com atenção especial às publicações dos últimos 5 anos, o assunto foi abordado com relação à conceituação, ao diagnóstico, estadiamento e tratamento. Resultado: A DGNAF está emergindo como uma das maiores causas de doença crônica do fígado e representa o componente hepático da síndrome metabólica, caracterizada por obesidade, hiperinsulinemia, resistência periférica à insulina, diabete, hipertrigliceridemia e hipertensão. O tratamento cirúrgico da obesidade mórbida faz parte do arsenal terapêutico da DGNAF. Conclusão: $O$ tema foi amplamente discutido, baseado em estudos recentes.

Descritores: Esteato-Hepatite Não Alcoólica. Fibrose Hepática. Obesidade Mórbida. Cirurgia Bariátrica.

\section{Introduction}

Nonalcoholic fatty liver disease (NAFLD) represents a spectrum of liver disorders that are unified histologically by macrovesicular hepatic steatosis exceeding 5 to $10 \%$ by weight, in the absence of excessive alcohol consumption. ${ }^{1}$ However, defining the amount of alcohol intake that should be considered excessive is controversial. Many centers accept a limit of 14 to 28 units of ethanol per week (20-40g/ day in men and $20 \mathrm{~g}$ /day in women), whereas other centers have set a limit of 7 units per week ( $10 \mathrm{~g}$ /day). ${ }^{1}$ Recently, there has been mounting evidence that NAFLD is the hepatic component of the metabolic syndrome, whose central features are obesity, hyperinsulinemia, peripheral insulin resistance, diabetes, hypertriglyceridemia, and hypertension. Younossi subdivided NAFLD into four specific histological types: type 1- hepatic steatosis; type 2- steatohepatitis; type 3- steatonecrosis; type 4steatonecrosis in the Mallory bodies or fibrosis. Patients with NAFLD diagnosed with steatonecrosis by means of liver biopsy have the worst prognosis, generally associated with progression to cirrhosis and death related to the hepatic condition. $^{2}$ Hepatic steatosis is the NAFLD histological subtype characterized by fat accumulation, especially triglycerides, in ballooned hepatocytes. Lipid accumulation may have central lobular distribution in the slightly and moderately obese patients, or diffuse distribution in the severely obese ones. ${ }^{3}$ The cell nucleus is shifted to the periphery. This subtype is a very common finding in liver biopsy specimens. In routine clinical practice, most cases are attributable to excess alcohol intake; however, it can also occur in association with a wide range of diseases, toxins, and drugs, especially morbid obesity and non-insulin dependent diabetes mellitus. The prognosis of this subtype has traditionally been considered to be benign. ${ }^{4}$ The nonalcoholic steatohepatitis (NASH), also an NAFLD subtype, is considered to be one of the most common causes of liver disease worldwide. ${ }^{3}$ The term NASH, coined by Ludwig et al. in $1980^{5}$ to describe the findings of liver biopsy in patients with steatohepatitis in the absence of significant 
alcohol intake, has served the field well by bringing attention to this pathology and promoting further research in this area. However, defining NASH as nonalcoholic is troublesome for the pathologist because this condition is histologically similar to alcohol hepatitis, with the presence of macrovesicular steatosis, lobular mixed inflammatory infiltration, hepatocellular ballooning, and necrosis. ${ }^{6}$ An alternative name has been recently proposed for NASH metabolic steatohepatitis - but it has not been uniformly accepted. Another alternative under consideration by pathologists is to further simplify the nomenclature by reporting biopsy results as steatohepatitis only, leaving it to the clinician to assign etiology and risk factors. NASH has been found to accompany obesity, diabetes, hyperlipidemia, protein malnutrition, jejunoileal bypass, intravenous hyperalimentation, and the use of hepatotoxic drugs. Patients with resistance to insulin and obesity are at a higher risk of developing the NASH subtype. ${ }^{7}$

\section{Histopathology}

Liver injury histological findings range from simple steatosis and NASH to increased fibrosis and cirrhosis. Some histological features are important for diagnosis, as shown in Chart 1. Nowadays, there is a significant diversity of score systems being employed to grade and stage NAFLD. The lack of standardization of histological findings clearly suggests the need for a simpler, more reproducible, and more precise grading and staging system. The most frequently used classification systems are the following: (Chart 2, 3,4 and 5)

CHART 1 - Histological Abnormalities in NASH

\begin{tabular}{|c|c|}
\hline Necessary Histological Components & $\begin{array}{l}\text { - Steatosis, macro> micro; accentuated in zone } 3 \\
\text { - Mixed, mild lobular inflammation } \\
\text { - Hepatocellular ballooning, most apparent near } \\
\text { steatotic liver cells, typically in zone } 3\end{array}$ \\
\hline Usually present, but not necessary for diagnosis & $\begin{array}{l}\text { - Zone } 3 \text { perisinusoidal fibrosis } \\
\text { - Zone } 1 \text { hepatocellular glycogenated nuclei } \\
\text { - Lipogranulomas in the lobules, usually small } \\
\text { - Fat cysts }\end{array}$ \\
\hline May be present & $\begin{array}{l}\text { - Mallory bodies, usually in zone } 3 \\
\text { - Mild granular periportal hepatocellular iron or } \\
\text { scattered iron granules in sinusoidal lining cells } \\
\text { - Megamitochondria in hepatocytes }\end{array}$ \\
\hline $\begin{array}{l}\text { Unusual for NASH; consideration of other conditions } \\
\text { recommended }\end{array}$ & $\begin{array}{l}\text { - Macrovesicular steatosis }<33 \% \\
\text { - Purely or predominantly microvesicular steatosis } \\
\text { - Sclerosing hyaline necrosis, veno-occlusive lesions, } \\
\text { perivenular fibrosis } \\
\text { - Portal inflammation greater than lobular inflammation } \\
\text { - Frequent eosinophils in portal or lobular inflammation } \\
\text { - Portal or periportal fibrosis greater than } \\
\text { perisinusoidal fibrosis } \\
\text { - Acute cholestasis } \\
\text { - Chronic cholestasis } \\
\text { - Accumulation of granular iron greater in zone } 1 \text { than } \\
\text { in zone } 3\end{array}$ \\
\hline
\end{tabular}

CHART 2-Liver steatosis scoring systems

\begin{tabular}{|cll|}
\hline Grade & Brunt's scale $^{8}$ & Dixon's scale $^{9}$ \\
\hline 0 & $0 \%$ biopsed hepatocytes affected & No steatosis \\
1 & $<33 \%$ biopsed hepatocytes affected & $<5 \%$ of hepatocytes affected \\
2 & $33 \%-66 \%$ biopsed hepatocytes affected & $5-25 \%$ of hepatocytes affected \\
3 & $>66 \%$ hepatocytes affected & $25-75 \%$ of hepatocytes affected \\
4 & - & $>75 \%$ of hepatocytes affected \\
\hline
\end{tabular}




\section{Necroinflammatory scoring systems for steatohepatitis}

a) Brunt's ${ }^{8}$ scale (based on the fact that no histological feature analyzed in isolation expresses the grade of NASH activity precisely; a combination of variables must therefore be taken into account)

Grade 1: mild- Liver biopsies meet the minimum criteria for the diagnosis of steatohepatitis with some degree of hepatocellular steatosis, and characteristic lobular mixed inflammation. Intra-acinar inflammation is scattered and mild and consists of small collections of polymorphonuclear leukocytes with or without lymphocytes. Occasional microgranulomas and lipogranulomas may be seen. Although the amount of steatosis is usually less than $33 \%$ of the biopsed material, steatosis up to $66 \%$ of the material but with mild inflammation only may be present. Steatotic hepatocytes may be either scattered throughout the lobules or concentrated in zone 3 . In the latter case, the inflammatory component is very mild. Ballooning and disarray are minimally present, if at all. Chronic portal inflammation is absent or mild. Portal inflammation is not seen in the absence of lobular inflammation.
Grade 2: Moderate- Liver biopsies show the combination of morphological changes that range from those described for the mild grade to those seen in the severe grade. Steatosis is more markedly noted and may be seen in up to or in more than $66 \%$ of the hepatocytes. Ballooning and disarray are always present and are predominantly found in zone 3 hepatocytes. Ballooning is more commonly present in hepatocytes adjacent to those most distended by steatosis. Intra-acinar inflammation, as described for grade 1 , is more noticeable and is typically associated with zone 3 perisinusoidal fibrosis. Microgranulomas and lipogranulomas, sometimes quite small, are nearly always present. Portal inflammation is at least mild.

Grade 3: Severe- Steatosis is usually panacinar or involves the entire regenerative nodule in cirrhotic parenchyma. Ballooning and disarray are consistently present, predominantly in zone 3. Lobular inflammation is increased compared with grade 2 . Portal inflammation is similar to that described for grade 2 .

b) Scheuer's scale modified by Gabriel ${ }^{10}$ ( Chart 3)

Liver fibrosis staging (Chart 4 and 5)

CHART 3 - Portal activity
\begin{tabular}{|l|l|}
\hline Grade 1 & $\begin{array}{l}\text { Portal Activity: portal inflammation only } \\
\text { Lobular activity: inflammatory cells but no hepatocellular damage }\end{array}$ \\
\hline Grade 2 & $\begin{array}{l}\text { Portal activity: mild or localized interface hepatitis } \\
\text { Lobular activity: focal necrosis or apoptosis }\end{array}$ \\
\hline Grade 3 & $\begin{array}{l}\text { Portal activity: moderate or more extensive hepatitis } \\
\text { Lobular activity: severe hepatocellular damage }\end{array}$ \\
\hline Grade 4 & $\begin{array}{l}\text { Portal activity: severe and widespread hepatitis } \\
\text { Lobular activity: bridging confluent necrosis }\end{array}$ \\
\hline
\end{tabular}

CHART 4 - Brunt's scale ${ }^{8}$
\begin{tabular}{|l|l|}
\hline F0 & Absent \\
\hline F1 & Zone 3 perisinusoidal/ pericellular fibrosis; focal or extensive \\
\hline F2 & Perisinusoidal/pericellular fibrosis with focal or extensive periportal fibrosis \\
\hline F3 & Perisinusoidal/pericellular fibrosis with focal or extensive bridging fibrosis \\
\hline F4 & Cirrhosis \\
\hline
\end{tabular}

CHART 5 - Scheuer's scale modified by Gabriel ${ }^{10}$
\begin{tabular}{|l|l|}
\hline F0 & Absent \\
\hline F1 & Portal fibrosis confined to portal tracts \\
\hline F2 & Periportal-periportal fibrosis or portal-portal septa, but intact vascular relationship \\
\hline F3 & Septal (bridging) fibrosis with distorted structure but no obvious cirrhosis \\
\hline F4 & Probable or definite cirrhosis \\
\hline
\end{tabular}




\section{Epidemiology}

Paralleling the rise in the incidence of obesity and diabetes worldwide (approximately 15 to $20 \%$ of the Western adult population is obese), the nonalcoholic fatty liver disease is being increasingly recognized as one of the major causes of chronic liver disease. ${ }^{11}$ Fatty liver disorders are common among the asymptomatic obese, and the incidence of this disorder in liver biopsy specimens of obese individuals range between 60 and $100 \%$ of the cases. ${ }^{3}$ Concerning the more severe NAFLD types, various studies have implicated high levels of obesity in these disorders. Steatohepatitis has been shown to occur in 24 to $95 \%$ of the patients, whereas fibrosis has been implicated in 6 to $74 \%$ of the cases, and cirrhosis in 0 to $24 \% .^{3,12,13}$ On the other hand, a number of epidemiological studies have demonstrated obesity in 70 to $100 \%$ of NASH cases. Most of the patients who have NASH are 10 to $40 \%$ over their ideal weight. Although individuals with normal body mass index (BMI) may also have NASH, it is more frequently found in patients who are obese or have the metabolic syndrome. ${ }^{7} \mathrm{NASH}$ is the major cause of cryptogenic cirrhosis, and it follows alcohol and viral hepatitis as the most common cause of chronic liver parenchyma damage. ${ }^{14}$ Between 11 and $16 \%$ of the patients that have undergone liver transplantation develop NASH due to cryptogenic cirrhosis, thus suggesting that the fatty liver disease was responsible for most of the cirrhosis cases. On the other hand, recurrence of NASH after liver transplantation occurs in $33 \%$ of the patients. ${ }^{15}$

\section{Natural History}

Little was known about the natural history of NAFLD before recent work began to elucidate some pending questions. ${ }^{16}$ In one of such works, 103 patients with NAFLD were followed from 1980 to 2003 by means of repeat liver biopsy. Sixty-seven percent of these patients were obese and the mean time interval between the first and the last biopsy was 3.2 years. It was observed that $37 \%$ of the patients increased in fibrosis stage, $34 \% \mathrm{did}$ not change, and $29 \%$ regressed. This regression occurred even though the patients had not lost weight. However, other variables, such as increased physical activity and better glycemic controls, were not studied in this work. Fibrosis regression was very slow, it would take 10 years overall, with considerable variability among patients. As for fibrosis progression, it occurred more rapidly in diabetics and in patients with higher BMI. The authors concluded that these patients should thus be targeted for therapeutic intervention to prevent disease progression. ${ }^{16}$ In the absence of fibrosis or steatohepatitis, nonalcoholic liver steatosis is considered a benign condition, contrary to alcoholinduced liver steatosis, which progresses to cirrhosis even in the absence of steatohepatitis or fibrosis if alcohol intake is continued. ${ }^{4}$ Nevertheless, although uncommon, progression to cirrhosis in mild cases of steatosis may occur and any amount of fat is believed to be the possible sensitizing factor predisposing the individual to liver damage by other agents. ${ }^{1}$ It is estimated that 15 to $20 \%$ of the patients with NASH will progress to cirrhosis. It is becoming increasingly evident that the metabolic syndrome is associated with the progression of fibrosis. ${ }^{7}$ In a prospective work with 127 morbidly obese patients submitted to gastric bypass, Boza et al. demonstrated that insulin-resistance, as determined by the homeostasis Model Assessment (HOMA-IR) (Matthews), and changes in AST values are predictors of NASH. More specifically speaking, $7.8 \%$ of the patients with HOMAIR $<5.8$ and $\mathrm{AST}<31 \mathrm{UI} / \mathrm{L}$ had NASH in the biopsy, whereas NASH was present in $50 \%$ of the patients with HOMA-IR and AST values higher than the ones mentioned above. Moreover, if the latter patients also had diabetes mellitus type 2, NASH was present in 75\% of them. ${ }^{17}$ A 5- and 10-year survival in NASH has been estimated at $67 \%$ and $59 \%$, respectively. ${ }^{1}$

\section{Pathophysiology}

The pathophysiology of NAFLD is summarized in Figure 1. Some works have provided evidence that NAFLD is more prevalent in males. In an attempt to understand this phenomenon, part of the pathophysiology of NAFLD has been elucidated. Males generally have greater abdominal visceral fat mass, which has a lipolytic nature and is in close proximity with the portal system. This fat is also more lipolytically active than subcutaneous fat due to its lower sensitivity to insulin and a higher concentration of beta-receptors. Furthermore, visceral fat is known to drain directly into the portal system, exposing the liver to large amounts of free fatty acids that may be oxidized or synthesized to triglycerides and either stored (steatosis) or secreted into the circulation. ${ }^{18}$ Exposure of the liver to large amounts of free fatty acids increases production of VLDLtriglyceride and cholesterol. High concentrations of free fatty acids also inhibit hepatic pyruvate oxidation by pyruvate kinase, with enhancement in liver gluconeogenesis and glucose output. In turn, increased glucose efflux estimulates insulin production, which impairs the sensitivity of peripheric receptors to insulin. All these factors, allied with the toxicity free fatty acids exert on beta cells, may cause hyperglycemia and diabetes. ${ }^{18}$ Oxidative stress is frequently considered to be a central mechanism of hepatocellular injury in NASH. The presence of free fatty acids may also contribute to such injury because they can be directly toxic to hepatocytes. ${ }^{1}$ Peripheral insulin resistance has been implicated as the key mechanism in the pathogenesis of NASH. Numerous substances, mainly released by adipocytes and with a venous flux directed toward the portal vein, can potentially contribute to insulin resistance. These include proinflammatory cytokines such as interleukin-6 and tumor necrosis factor a, as well as angiotensinogen, leptin, resistin, and adiponectin. ${ }^{19,20}$ Adiponectin is an antidiabetic and antiatherogenic acting polypeptide strongly correlated with systemic insulin sensitivity. It increases fatty acid beta-oxidation in muscle, enhances hepatic insulin action, and decreases lipid accumulation in macrophages. ${ }^{19} \mathrm{Xu}$ et al have reported that adiponectin administration alleviates NAFLD in mice by improving hepatomegaly and steatosis and attenuating 
hepatocellular inflammation. ${ }^{21}$ Recently, research has focused not only on adiponectin but also on its receptors adipoRI and adipoRII. Decreased adiponectin and adipoRII liver expressions were detected in liver biopsies of patients with NASH if compared with patients with simple steatosis, suggesting that these changes are important in the pathophysiology of NAFLD. ${ }^{22}$

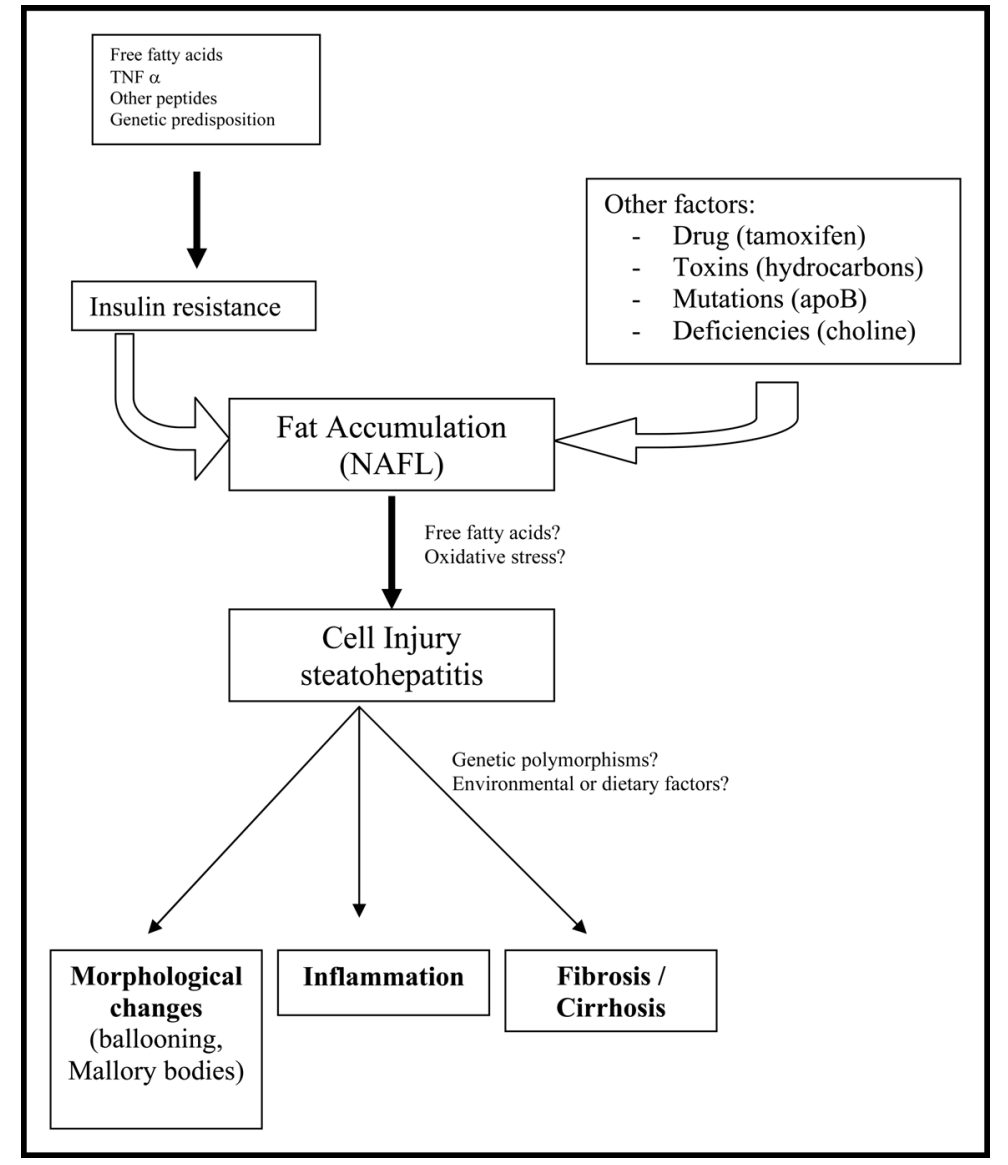

FIGURE 1 - Pathophysiology of the nonalcoholic fatty liver disease

\section{Diagnosis}

\section{- Symptoms}

Once the majority of the NAFLD patients are clinically silent, investigation generally starts following casual detection of abnormal liver enzyme levels at routine evaluation. When present, the symptoms correlate poorly with the severity of the condition, and they can be mistaken for other illnesses and non-pathogenic signs such as fatigue, right upper quadrant pain, hepatomegaly, obesity, acanthosis nigricans, among others.

\section{- Complementary tests}

Biochemical tests may give evidence of elevation of both AST levels and the AST:ALT ratio, besides detecting increased levels of g-glutamyltransferase and alkaline phosphatase, hyperglycemia, and lipidemia. However, it is known that advanced liver disease may be present even though the level of liver enzymes is normal. Imaging in NASH can be carried out by means of ultrasound, computerized tomography, or magnetic resonance. Nevertheless, all these tests are insensitive to degrees of steatosis less than $30 \%$ and they do not efficiently stage NAFLD. Although the presence of NAFLD is often suspected clinically, no biochemical or radiological tests reliably establish the diagnosis. Shalhub et al demonstrated that the liver macroscopic appearance is not predicitive of NASH. Therefore, liver biopsy remains the goldstandard for diagnosing, grading, and staging NAFLD. Needle liver biopsy remains more sensitive and specific than wedge liver biopsy. ${ }^{23}$ However, the value of routine liver biopsy is being questioned because of its significant risks and cost, as well as due to the lack of effective therapy for NAFLD . Liver biopsy has been associated with significant sampling error in patients with chronic parenchyma disease, because the diagnostic tissue represents only a minute fraction of the parenchyma. ${ }^{24}$ In a study in which Janiec et al. examined paired liver biopsies from the right and left hepatic lobes of morbidly obese patients sampled during bariatric surgery, they found that the lobes differed in histopathological staging in 30\% of the NAFLD patients. The authors thus suggested that an adequately sized biopsy should have at least $1.0 \mathrm{~cm}$ in length and 10 portal tracts, and not 6 as previously recommended. ${ }^{24}$ Current recommendations for liver biopsy are: ALT greater than twice normal; AST>ALT; at least moderate central obesity; diabetes melitus type 2 or impaired glucose tolerance; hypertension; and hypertriglyceridemia; and in the intraoperatory of the bariatric surgery. 


\section{Management}

With respect to the management of NAFLD, studies published to date are limited by the small number of patients, the variations in the definition of $\mathrm{NASH}$, and the study end points. Resolution of histological abnormalities as determined by liver biopsy should be the main target of the treatment. ${ }^{1}$ The management of NASH remains empirical and limited to the treatment of the conditions associated with it, such as diabetes, obesity, and hyperlipidemia. The use of hepatotoxic pharmacological agents like amiodarone, tamoxifen, estrogens, nifedipin, and diltiazem should be avoided. If the patient has a history of alcohol abuse, alcohol intake should be prohibited. Ursodeoxycholic acid has been extensively studied in other liver diseases. It acts as a cytoprotective agent for the hepatocyte, and has shown to be a promising therapy for NASH in some preliminary studies. ${ }^{25}$ Some antioxidant agents and drugs employed in iron reduction therapy have also been investigated for the treatment of NASH, leading to satisfactory results. Among the promising agents are vitamin E, S-adenosylmethionine, and $\mathrm{N}$-acetylcysteine ${ }^{26}$ Exercise and diet continue to be the cornerstones of NAFLD management. Some works have demonstrated that weight loss and exercising were responsible for decreased levels of liver injury. ${ }^{27}$ Because weight loss for the treatment of both NASH and steatosis has become a focus of clinical research, bariatric surgery is currently believed to be the only approach to offer significant and sustained weight loss for the majority of patients with severe obesity. In fact, bariatric surgery is considered the only effective option for sustained massive weight loss in the case of the morbidly obese, and it has been adopted worldwide according to the protocol set by the United States National Institute of Health in 1991. ${ }^{9}$ Jejunoileal bypass was previously used to treat obesity, but it induced or worsened hepatic changes related to NAFLD, with rapid progression to liver failure. As a result, it has now been abandoned as a surgical treatment option. More recently, other surgical techniques have been associated with significant improvement in comorbities and in the patient's quality of life. Recently, a Swedish group examined results from over 4,000 morbidly obese subjects randomized to bariatric surgery versus conventional clinical management. These researchers demonstrated that surgery had long-term beneficial effects on cardiovascular risk factors, diabetes, and lifestyle. ${ }^{28}$ In a study of 51 morbidly obese patients with a mean BMI of $52.8 \mathrm{~kg} / \mathrm{m}^{2}$ submitted to vertical gastroplasty (Mason surgery), Stratopoulos et al. demonstrated that there was significant improvement in liver steatosis, steatohepatitis, and fibrosis after a mean weight loss of $66 \%$ excess weight over an average of 18 months..$^{29}$ In 2004, Dixon et al. evaluated 36 morbidly obese patients, 23 of which had NASH in the initial biopsy. The patients underwent laparoscopic adjustment gastric banding and, after losing an average of $34 \mathrm{Kg}$, a second biopsy revealed that only 4 patients fulfilled the criteria for NASH, which resolved in $82 \%$ of these patients. Furthermore, of 18 patients who had fibrosis in the beginning of the study, only 3 demonstrated fibrosis scores at the end of the investigation. ${ }^{9}$ Kral et al. studied 689 morbidly obese patients with NAFLD, submitted to bileopancreatic diversion (Scopinaro surgery), over a 10-year period. One hundred and four of these patients were reoperated for some reason, being therefore submitted to new liver biopsy, and they lost an average of
$38 \mathrm{~kg}$ over an average of 41 months after surgery. Twenty-eight of these patients showed a decrease in their fibrosis score, 42 patients exhibited increased fibrosis, 3 developed cirrhosis, and 34 remained with unchanged fibrosis. Furthermore, in the case of some subjects with cirrhosis in the first biopsy, the second biopsy showed decreased fibrosis scores, inflammation, and the presence of Mallory bodies. ${ }^{3}$ When Mottin et al. followed 90 morbidly obese patients with an average BMI of $46 \mathrm{Kg} / \mathrm{m}^{2}$ who had been submitted to gastric bypass (Fobi surgery), they observed significant improvement in hepatic steatosis histology, associated with weight loss. There was no worsening of histology. ${ }^{30}$ Because there are a number of techniques available for bariatric surgery, it is imperative to evaluate the risks and benefits of each type of surgery with respect to the evolution of NAFLD. It has been observed that $1.4 \%$ of the morbidly obese patients that underwent some type of bariatric surgery have cirrhosis. Although some improvement in cirrhosis has been reported after post-operative weight loss ${ }^{2}$, in subjects with more advanced disease liver transplantation is the only treatment available. However, many patients are poor candidates for transplantation due to comorbid conditions such as obesity and diabetes, not to mention the high rate of NASH recurrence in transplanted livers. ${ }^{15}$

\section{References}

1. Neuschwander-Tetri BA, Caldwell SH. Nonalcholic steatohepatitis: summary of na AASLD single topic conference. Hepatology. 2003; 37: 1202-19.

2. Younossi ZM, Gramlich T, Liu YC, Matteoni C, Petrelli M, Goldblum J, Rybicki L, McCullough, AJ. Nonalcholic fatty liver disease: assessment of variability in pathologic interpretations. Mod Pathol. 1998; 11: 560-5.

3. Kral JG, Thung SN, Biron S et al. Effects of surgical tratment of the metabolic syndrome on liver fibrosis and cirrhosis. Surgery. 2004; 135: 48-58.

4. Teli MR, James OF, Burt AD, Bennett MK, Day CP. The natural history of nonalcholic fatty liver: a follow-up study. Hepatology. 1995; 22: 1714-19.

5. Ludwig J, Viggiano TR, McGill DB, Oh BJ. Nonalcholic steatohepatitis: Mayo Clinic experience with a hitherto unnamed disease. Mayo Clin Proc. 1980; 55: 434-8.

6. Bacon BR, Farahvash MJ, Janney CG, NeuschwanderTetri BA. Nonalcholic steatohepatitis: an expanded clinical entity. Gastroenterology. 1994; 107: 1103-9.

7. Chitturi S, Farrel GC. Etiopathogenesis of nonalcholic steatohepatitis. Semin Liver Dis. 2001; 21: 27-41.

8. Brunt EM, Janney CG, Di Bisceglie AM, NeuschwanderTetri BA, Bacon BR. Nonalcholic steatohepatitis: A proposal for grading and staging the histological lesions. Am J Gastroenterol. 1999; 94: 2467-74.

9. Dixon JB, Bhathal PS, Hughes NR, O'Brien PE. Nonalcholic fatty liver disease: improvement in liver histological analysis with weight loss. Hepatology. 2004; 39: 1647-54.

10. Gabriel A, Ziólkolwski A. Proposition of histopathologic examination protocol of liver specimen in diagnosing chronic hepatitis. Pol Merk Lek. 1997; 2: 320-3. 
11. Flegal KM, Carroll MD, Kuczmarski RJ, Johhnson CL. Overweight and obesity in the United States: prevalence and trends, 1960-1994. Int J Obes Relat Metab Disord. 1998; 22:39-47.

12. Adler M, Schaffner F. Fatty liver hepatitis and cirrhosis in obese patients. Am J Med. 1979; 67: 811-6.

13. Younossi ZM, Diehl AM, Ong JP. Nonalcholic fatty liver disease: an agenda for clinical research. Hepatology. 2002; 35: 746-52.

14. Caldwell SH, Oelsner DH, Iezzoni JC, Hespenheide EE, Battle EH, Driscoll CJ. Cryptogenic cirrhosis: clinical characterization and risk factors for underlying disease. Hepatology. 1999; 29: 664-9.

15. Ong J, Younossi ZM, Reddy V, Price LL, GramlichT, Mayes J, Boparai N. Cryptogenic cirrhosis and postrasplantation nonalcholic fatty liver disease. Liver Transpl. 2001; 7: 797-801.

16. Adams LA, Sanderson S, Lindor K, Angulo P. The histological course of nonalcholic fatty liver disease: a longitudinal study of 103 patients with sequential liver biopsies. J Hepatol. 2005; 42: 132-8.

17. Boza C, Riquelme A, Ibanes L, Duarte I, Norero E, Viviani P, Soza A, Fernandez JI, Raddatz A, Guzman S, Arrese M. Predictors of nonalcholic steatohepatitis (NASH) in obese patients undergoing gastric bypass. Obes Surg. 2005; 15: 1148-53.

18. Wolf AM, Busch B, Kuhlmann HW, Beisiegel U. Histological changes in the liver of morbidly obese patients: correlations with metabolic parameters. Obes Surg. 2005; 15: 228-37.

19. Berg AH, Coombs TP, Scherer PE. ACRP30/adiponectin: an adipokine regulating glucose and lipid metabolism. Trends Endocrinol Metab. 2002; 13: 84-9.

20. Hotamisligil GS, Arner P, Caro JF, Atkison RL, Spiegelman BM. Increased adipose tissue expression of tumor necrosis factor-a in human obesity and insuline resistance. J Clin Invest. 1995; 95: 2409-15.

21. Xu A, Wang Y, Keshaw H, Xu LY, Lam KS, Cooper GJ. The fat-derived hormone adiponectin alleviates alcholic and nonalcholic fatty liver diseases in mice. L Clin Invest. 2003; 112:91-100.
22. Kaser S, Moschen A, Cayon A, Kaser A, Crespo J, PonsRomero F, Ebenbichler CF. Adiponectin and its receptors in nonalcholic steatohepatitis. Gut. 2005; 54: 117-21.

23. Shalhub S, Parsee A, Gallagher SF, Haines KL, Wilkomm C, Brantley SG, Pinkas H, Saff-Koche L, Murr MM. The importance of routine liver biopsy in diagnosing nonalcholic steatohepatitis in bariatric patients. Obes Surg. 2004 ; 14: 54-9.

24. Janiec DJ, Jacobson ER, Freeth A, Spaulding L, Blaszyk $\mathrm{H}$. Histologic variation of grade and stage of nonalcholic fatty livr disease in liver biopsies. Obes Surg. 2005; 15: 497-501.

25. Laurin J, Lindor KD, Crippin JS, Gossard A, Gores GJ, Ludwig J, Rakela J, McGill DB. Ursodeoxycholic acid or clofibrate in the treatment of nonalcholic-induced steatohepatitis: a pilot study. Hepatology. 1996; 23: 1464-7.

26. Gulbahar O, Karasu ZA, Ersoz G.. Treatment of nonalcholic steatohepatitis with $\mathrm{N}$-acetylcysteine [Abstract]. Gastroenterology. 2000; A1444.

27. Drenick EJ, Simmons F, Murphy JF. Effect on hepatic morphology of treatment of obesity by fasting, reducing diets and small bowel bypass. N Engl J Med. 1970; 282: 829-34.

28. Sjöström L, Lindroos AK, Peltonen M, Torgerson J, Bouchard C, Carlsson B, Dahlgren S, Larsson B, Narbo K, Sjöström CD, Sullivan M, Wedel H. Lifestyle, diabetes and cardiovascular risk factor 10 years after bariatric surgery. N Engl J Med. 2004; 351: 196-9.

29. Stratopoulos C, Papakonstantinou A, Terziz I, Spiliadi C, Dimitriades G, Komesidou V, Kitsanta P, Argyrakos T, Hadjiyannakis E. Changes in liver histology accompanying massive weight loss after gastroplasty for morbid obesity. Obes Surg. 2005; 15: 1154-60.

30. Mottin CC, Moretto M, Padoin AV, Kupski C, Glock L, Reichel CL, da Silva VD, da Silva JB. Histological behavior of hepatic steatosis in morbidly obese patients after weight loss induced by bariatric surgery. Obes Surg. 2005; 15: 788-93.

\section{Correspondence:}

Orlando de Castro e Silva Jr.

Rua Campos Salles, 809 - $9^{\circ}$ andar. CEP: 14015-110

Centro, Ribeirão Preto - SP - Brazil.

Email: orlando@fmrp.usp.br

\section{How to cite this article}

Salgado JrW, Santos JS, Sanakarankutty AK, Castro e Silva O. Non-alcoholic fatty liver disease and obesity. Acta Cir Bras. [serial on the Internet] 2006;21 Suppl 1. Available from URL: $\underline{\text { http://www.scielo.br/acb }}$ 